Kong. Res. J. 1(2): 109-111, 2014

Kongunadu Arts and Science College, Coimbatore

\title{
DIVERSITY OF BASIDIOMYCETES IN DODDANNI FOREST, THE NILGIRIES
}

\author{
Sindhu, $\mathbf{S}^{*}$. and S. Manorama \\ Department of Botany, Kongunadu Arts and Science College (Autonomous), Coimbatore. \\ *E.mail: ssindhu389@gmail.com
}

\begin{abstract}
Studies on the taxonomy and diversity of macro fungi are gaining importance as many macro fungi are becoming extinct and facing threat of extinction because of habitat destruction. Present study deals with the diversity of macro fungi in Nilgiri Biosphere Region (NBR) of Western Ghats. Extensive surveys were conducted from June 2011 to February 2012, where collection, preservation and photo of macro fungal carried the genera like are Boletus, Suillus, Leccinum, Tylopilus, Lactarius, Russula, Amanita, Tricholoma, Stropharia, Entoloma, Cortinarius, Scleroderma and Agrocybe were identified. A total of 20 species were collected belonging to 10 genera. Also the temperature, rainfall and the relative humidity of the study area was noted periodically. This preliminary study shows that the forest is very rich in mushroom diversity.
\end{abstract}

Key-Words: Nilgiri Biosphere Region (NBR), Maccro fungi, Diversity, climatic data.

\section{INTRODUCTION}

Fungi are a very large, diverse group of living organisms found in nearly all ecosystems. Fungi which form an important component of the forest ecosystem have been largely neglected in any of the biodiversity studies of a given area and play key roles in all ecosystems as saprophytic, pathogens and symbionts (Mueller et al., 2007; Schmit and Mueller, 2007). The present correspondence is an attempt to give a broad picture of the biodiversity of a particular group of fungi, viz. members of order Agaricales, Class Basidiomycetes in the NBR. Natarajan et al. (2005) present a broad picture of the biodiversity of members of Agaricales, a particular group of fungi in the class Basidiomycetes, in the Nilgiri Biosphere Region (NBR) of Western Ghats. There are a large number of undescribed species present in this region.

Currently, there is little knowledge of mycodiversity and also a deficiency of systematic taxonomic work achieved in NBR. The purpose of the present survey was to identify the mushrooms up to genus and species level, to record and compare the diversity of mushrooms to other areas and to bring awareness among people to conserve mushrooms. Basidiomycetes fungi have been known to synthesize a vast array of secondary metabolites that possess beneficial biological activities (Dong-Ze et al., 2008). The medicinal properties of basidiomycetae mushrooms are frequently described in ancient cultures and a few have been developed into pharmacological applications today. In Asian cultures, the holocarp of several genera are eaten, included as a garnish, or boiled as teas and applied as therapies for a variety of human ailments ranging from the common cold to cure for certain forms of cancers (Loreto Robles-Hernandez, 2008).

A total number of 223 species belonging to 61 genera have so far been reported from the Nilgiri Biosphere Reserve (Natarajan, 2005). Many basidiomycetae fungi serve an important ecological role as wood decomposers. Our main objectives of this study is to target the diversity of macro fungi, in Nilgiri Biosphere Region (NBR) of Western Ghats, India.

\section{MATERIALS AND METHODS}

\subsection{Study area}

The present study area Doddani is located in a distance of $15 \mathrm{~km}$ from Kothagiri of Nilgiri District at a latitude of $10^{\circ} 24^{\prime} \mathrm{N}$ and a longitude of $63^{\circ} 36^{\prime} \mathrm{E}$ at an altitude of $1900 \mathrm{~ms}$ above msl with 170ha. The study area is situated at sub-tropical forest region.

\subsection{Climatic data}

The climatic data of the study area for the study period of 9 months from June, 2011 to February, 2012 is given in table 1. The temperature during the study period was varied between 19 and $23^{\circ} \mathrm{C}$. The rainfall during the study period was about $180 \mathrm{~mm}$. The relative humidity was existing between 93 and 15 percent.

\section{RESULTS AND DISSCUSSION}

The climatic factor of the study area is given in Table 1. Maximum and minimum temperature, relative humidity and rainfall were observed from June 2011 to February 2012. The highest maximum temperature was $25^{\circ} \mathrm{C}$ during September December 2011. The highest minimum temperature 
was noted as $20^{\circ} \mathrm{C}$ on June, 2011 and the lowest minimum was $10^{\circ} \mathrm{C}$ from July - December 2011. The average annual rainfall during the study period June, 2011 was 157.44. The precipitation was mainly through south-west (June-August) and north-east (October - November) monsoon. The relative humidity during study period ranged between 70 and $95 \%$. Velocity of wind was moderate.

Table 1: Climatic data of the study area.

\begin{tabular}{lcccc}
\hline \multirow{2}{*}{$\begin{array}{c}\text { Year and } \\
\text { month }\end{array}$} & \multicolumn{2}{c}{$\begin{array}{c}\text { Temperature } \\
{ }^{\circ} \mathrm{C}\end{array}$} & $\begin{array}{c}\text { Rainfall } \\
\text { (mm) }\end{array}$ & $\begin{array}{c}\text { Relative } \\
\text { humidity (\%) }\end{array}$ \\
\cline { 2 - 3 } & Max & Min & $\mathbf{2 0 1 1}$ & 75 \\
June & 22 & 20 & 119 & 81 \\
July & 21 & 10 & 161 & 70 \\
August & 22 & 10 & 126 & 80 \\
September & 20 & 10 & 179 & 93 \\
October & 20 & 10 & 263 & 91 \\
November & 20 & 10 & 244 & 90 \\
December & 20 & 10 & 89 & \\
& \multicolumn{5}{c}{20} & & 90 \\
January & 22 & 15 & 110 & 95 \\
February & 25 & 15 & 126 & \\
\hline
\end{tabular}

Table 2: Edible status of collected Basidiomycetes.

\begin{tabular}{ccc}
\hline Family & Genus & No. of Species \\
\hline Boletaceae & Boletus & 2 \\
& Suillus & 2 \\
Suillaceae & Leccinum & 1 \\
& Tylopilus & 1 \\
Russulaceae & Lactarius & 2 \\
& Russula & 2 \\
Amanitaceae & Amanita & 3 \\
Tricholomataceae & Tricholoma & 1 \\
Strophariaceae & Stropharia & 2 \\
Entolomataceae & Entoloma & 1 \\
Cortinariaceae & Cortinarius & 1 \\
Sclerodermataceae & Scleroderma & 2 \\
Bolbitiaceae & Agrocybe & 1 \\
\hline
\end{tabular}

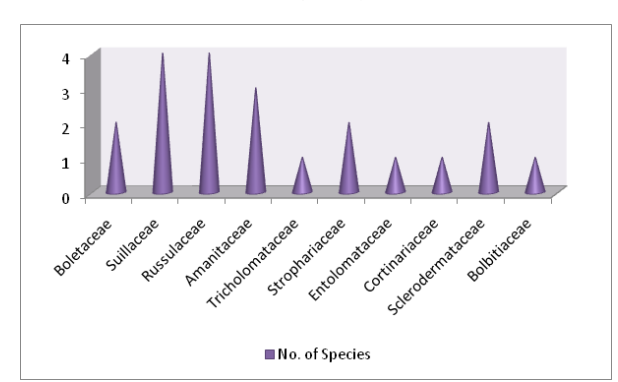

Table 3: Distribution of different species and family wise distribution of mushrooms of subdivition Basidiomycotina

\begin{tabular}{cllc}
\hline Sl.No. & Family & Species & Total \\
\hline 1. & Boletaceae & $\begin{array}{l}\text { Boletus edulis, Boletus pulverulentus } \\
\text { Suillus americanus, Suillus neoalbidipes, Leccinum fibrillosum, Tylopilus } \\
\text { 2yaneotinctus }\end{array}$ & 2 \\
3. & Suillaceae & Ractarius lignyotellus, Lactarius piperatus, Russula fragrantissima, & 4 \\
& Russulaceae & Russula ventricosipes & 2 \\
4. & Amanitaceae & Amanita flavoconia, Amanita muscaria & 1 \\
5. & Tricholomataceae & Tricholoma caligatum & 2 \\
6. & Strophariaceae & Stropharia hardii, Stropharia rugosoannulata & 1 \\
7. & Entolomataceae & Entoloma bloxamii & 1 \\
8. & Cortinariaceae & Cortinarius malicorius & 2 \\
9. & Sclerodermataceae & Scleroderma citrinum, Scleroderma michiganense & 1 \\
10. & Bolbitiaceae & Agrocybe paludosa & \\
\hline
\end{tabular}

The mycofloristic survey of Doddanni forest has several interesting mushrooms belongs to the Class Basidiomycetes. Based on Alexopolous and Mims system of classification, the collected mushrooms are coming under the Class Basidiomycetes, Order Agaricales, Lycoperdales and Phallales. Among these 3 orders, majority of the members are coming under Agaricales, which is followed by Lycorperdales and Phallales. The collected mushrooms are listed (Table-3).
The distribution of mushrooms in forest is higher than the grasslands because of the high nutrient contents. The occurrence of mushrooms is more in rainy season than the summer season (Ramsbottom, 1967). Among the 20 mushroom species, 8 edible belonging to the family Russulaceae, Suillaceae and Boletaceae. The family Russulaceae having 4 edible mushrooms, whereas in Suillaceae 2 edible mushrooms were collected. The same Agaricus species were collected as wild form in two localities of Himachal Pradesh (Upadhyay, et al.,2004). During the collected Basidiomycetes, the 
families like Boletaceae have 4 species and Russulaceae with 4 species, whereas Amanitaceae and Sclerodermataceae are with 2 species each in Doddanni forest.

During the course of mycofloristic survey of Doddanni forest, a high diversity of macrofungi, were encountered. Among the fungus Amanita flavoconia an edible mushroom abundantly present in the study area. Some species of Amanita were reported Sri Lanka, India, China, South Korea, Japan, U.S.A. (Vrinda et al., 2005). The other species A.hemibapha first described from Sri Lanka is a tropical relative of A.caesarea. A.muscaria, poison mushroom also collected in the study area.

During the survey genus lactarius sp. Of the family Russulaceae found more in different parts of the study area. It is also macrofungi having some interesting features. The same genus also recorded in North Western Himalaya region by (Das and Sharma, 2004).

Murali et al. (2007) studied foliar fungal endophytes of fifteen tree species from tropical dry thorn forest and tropical dry deciduous forest in Madumalai Wildlife Sanctuary, Nilgiri Biosphere Reserve, Southern India.

\section{CONCLUSION}

The fungi are an important component of the forest and grassland ecosystem which has been largely neglected by many biodiversity studies. So the present study has undertaken the biodiversity of the Basidiomycetes in the particular area of the Nilgiri district. This study indicates that, large number of fungi of this group occurs in the NBR of Tamil nadu and Kerala.

\section{REFERENCES}

Bilgrami, K., S. Jammaludin and M.A. Rizvi, (1979). Fungi of India. Part-II. Today and Tomorrow's Printers and Publishers, New Delhi.

Butler, E.J. and G.R. Bisby, (1931). The Fungi of India. Imp. Counc. of Agri Res. India, Sci. Mono 1, XVIII. Calcutta, pp: 237.
Das, K. and J.R. Sharma. (2004) - Lactarius in Kumaon Himalaya 2. New and interesting species of subgenus Plinthogali. Mycotaxon 89, 289-296.

Dong-Ze, L., J. Rui-Rui, W. Fei and L. Ji-Kai, (2008). A new Spiroaxane sesquiterpene from cultures of the Basidiomycetes Pholiata adiposa. Zeitschrift fu Naturforschung. 63: 111 - 113.

Mueller, G.M., J.P. Schmit, P.R. Leacock, B. Buyck, J. Cifuentes, D.E. Desjardin, R.E. Halling, K. Hjortstam, T. Iturriaga, K.H. Larsson, D.J. Lodge, T.W. May, D. Minter, M. Rajchenberg, S.A. Redhead, L. Ryvarden, J.M. Trappe, R. Watling, Q. Wu. (2007). Global diversity and distribution of acrofungi. Biodiversity and Conservation, 16: 37-48.

Natarajan, K., K. Narayanan, C. Ravindran and V. Kumaresan. (2005). Biodiversity of agarics from Nilgiri Biosphere Reserve, Western Ghats, India. Current Science, 88(12), 1890-1893

Robles-Hernández Loreto, Ana Cecilia-GonzálezFranco, Juan Manuel Soto-Parra and Federico Montes- Domínguez.R. (2008). Review of agricultural and medicinal applications of basidiomycete mushrooms. Tecnociencia Chihuahua 2(2): 95-107.

Schmit, J.P., G.M. Mueller. (2007). An estimate of lower limit of global fungal diversity. Biodiversity and Conservation, 16: 99-111.

Upadhyay, R.C. and Amanjeet Kaur. (2004). Taxonomic studies on light spored agarics new to India. In: Mushroom Research 13(1):1-6

Vasudeva, R.S., (1960). The fungi of India (revised) I.C.A.R. New Delhi.

Vrinda, K.B., C.K. Pradeep and S. Kumar. (2005). Occurrence of a lesser known edible Amanita in the Western Ghats of Kerala. Mushroom Research 14(1): 5-8. 